\title{
Intelligent Selection Tools
}

\author{
William A. Barrett \\ william_barrett@byu.edu \\ Eric N. Mortensen \\ L. Jack Reese
}

Follow this and additional works at: https://scholarsarchive.byu.edu/facpub

Part of the Computer Sciences Commons

\section{Original Publication Citation}

E. N. Mortensen, L. J. Reese, and W. A. Barrett, "Intelligent Selection Tools," in Proc. IEEE:

Computer Vision and Pattern Recognition (CVPR '), Vol. II, pp. 776-777, Hilton Head, SC, June 2.

\section{BYU ScholarsArchive Citation}

Barrett, William A.; Mortensen, Eric N.; and Reese, L. Jack, "Intelligent Selection Tools" (2000). Faculty Publications. 598.

https://scholarsarchive.byu.edu/facpub/598

This Peer-Reviewed Article is brought to you for free and open access by BYU ScholarsArchive. It has been accepted for inclusion in Faculty Publications by an authorized administrator of BYU ScholarsArchive. For more information, please contact ellen_amatangelo@byu.edu. 


\title{
Intelligent Selection Tools
}

\author{
Eric N. Mortensen L. Jack Reese William A. Barrett \\ Brigham Young University
}

\begin{abstract}
Intelligent Scissors and Intelligent Paint are complementary interactive image segmentation tools that allow a user to quickly and accurately select objects of interest. This demonstration provides a means for participants to experience the dynamic nature of these tools.
\end{abstract}

\section{Introduction}

No fully automatic image segmentation technique currently yeilds satisfactory results over a broad class of image sources, content, and complexity. Thus, intelligent segmentation tools which exploit high level vision methods while requiring minimal human interaction become appealing. Intelligent Scissors and Intelligent Paint are complementary, general-purpose, object selection tools which allow rapid and accurate object segmentation from arbitrarily complex backgrounds using simple gesture motions with a mouse. Intelligent Paint allows a user to efficiently select the region associated with an object of interest while with Intelligent Scissors, a human operator can quickly define object boundaries. Both tools utilize tobogganing to partition an image into homogeneous regions which are effectively identical to the catchment basins produced by computing the watershed of the image's gradient magnitude map. These regions become the basis for region-based (Intelligent Paint) or boundary-based (Intelligent Scissors) object selection.

This demonstration provides hands-on experience with these two interactive object selection tools. Due to the dynamic nature of these tools' input and feedback, it is difficult to convey the utility of Intelligent Scissors and Intelligent Paint in print (or even in video). Unlike previous object selection methods where segmentation typically occurs only after user input is complete, Intelligent Scissors and Intelligent Paint integrate human input with the segmentation process to provide dynamic interaction and feedback between the user and the computation. Thus, this demonstration will allow participants to directly evaluate the usability and benefit of these two complementary tools.

\section{Intelligent Scissors}

Intelligent Scissors is a general purpose, interactive object selection tool which allows a user to choose a minimum cost contour segment corresponding to a portion of the desired object boundary. As the mouse position comes in proximity to an object edge, a live-wire [1] boundary "snaps" to and wraps around the object of interest. Since the user interactively selects a boundary from a collection of optimal solutions, the user knows exactly what the resulting contour will be during interaction.

Intelligent Scissors achieves this goal by imposing a weighted graph on the image and interactively computing the optimal path from a user selected "seed" point to all other points in the image using an efficient, linear-time implementation of Dijkstra's graph search. As the cursor moves, the optimal path from the pointer position to the seed point is displayed, allowing the user to select an optimal contour segment which visually corresponds to a portion of the desired object boundary. Compared to manual tracing (i.e., lassoing), object selection using Intelligent Scissors is many times faster, more accurate, and more reproducible [2] (see Figures 1 and 2).

Last year, we presented toboggan-based Intelligent Scissors [3] which uses tobogganing to partition an image into homogeneous regions and then imposes a weighted, planar graph onto the region boundaries. The region-based graph is many times smaller than the pixel-based version used in our previous Intelligent Scissors [2]. This reduces the size of the graph which greatly speeds up the graph search and increases interactive responsiveness. Further, the tobogganed regions provide an efficient framework for computing a 4-parameter edge model (providing sub-pixel localization, blur, and foreground/background color) and improved cursor snapping (to facilitate cursor placement on object edges).

\section{Intelligent Paint}

Intelligent Paint [4] uses a simple connect-and-collect strategy to quickly and accurately define an object's region. This strategy uses a new hierarchical tobogganing algorithm to automatically connect image regions that naturally flow together, and a user-guided, cumulative cost-ordered expansion interface to interactively collect those regions which constitute the object of interest. Each paint stroke interactively samples the properties of the underlying regions as the intelligent paint adaptively flows into similar neighboring regions. This strategy coordinates human-computer interaction to extract complex regions of interest from arbitrary backgrounds using simple paint strokes with a mouse.

While tobogganing at the pixel resolution creates highly oversegmented regions, subsequent tobogganing between previously computed regions produces a natural hierarchy of segmentations. Hierarchical tobogganing produces segmentations which are not dependent on heuristic parameters or thresholds, and which are largely associated with image objects at multiple resolutions (see Fig. 3).

Using Intelligent Paint is like using a can of spray paint-with a few enhancements. The user simply presses the mouse or pointer button to begin painting at the cursor position, then releases the button when finished painting (see Figures 4 and 5). While the button is pressed, Intelligent Paint does two things: 1) it automatically expands the painted region to fill the object of interest, and 2) it interactively responds to user input. Enhancements to this basic press-and-release interface include an undo feature to unpaint regions, a slow motion feature to paint with greater precision, and an Intelligent Eraser. 
Intelligent Paint uses an efficient cost-ordered collection algorithm and performs on-the-fly training using dynamically updated look-up tables, interactively spawned seed or sample regions, and adaptive cooling. This interface allows human input to guide the algorithm where the segmentation is difficult to compute, yet does not require input where the segmentation is easily computed.

\section{References}

[1] E. N. Mortensen, et al., "Adaptive Boundary Detection Using 'Live-Wire' Two-Dimensional Dynamic Programming," in IEEE Proc. Computers in Cardiology, 635-638, Oct. 1992.

[2] E. N. Mortensen and W. A. Barrett, "Interactive Segmentation with Intelligent Scissors," GMIP, 60(5): 349-384, Sept. 1998.

[3] E. N. Mortensen and W. A. Barrett, "Toboggan-Based Intelligent Scissors with a Four Parameter Edge Model," in CVPR, 452-458, 1999. (Available at http://rivit.cs.byu.edu/ enm/)

[4] L. J. Reese, Intelligent Paint: Region-Based Interactive Image Segmentation. Masters Thesis, Department of Computer Science, Brigham Young University, Provo, UT, Aug. 1999. (Available at http:// rivit.cs.byu.edu/ reese/DATA/thesis.pdf)

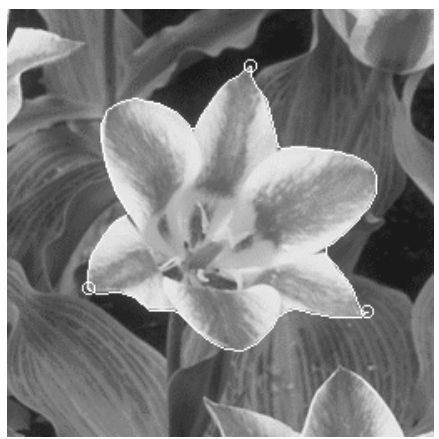

Figure 1: Full color image (printed grayscale) of a tulip (size: $256 \times$ 256). Boundary definition with Intelligent Scissors: 1.6 seconds with 2 seed nodes. (Color version available at http://rivit.cs.byu.edu/ enm/)

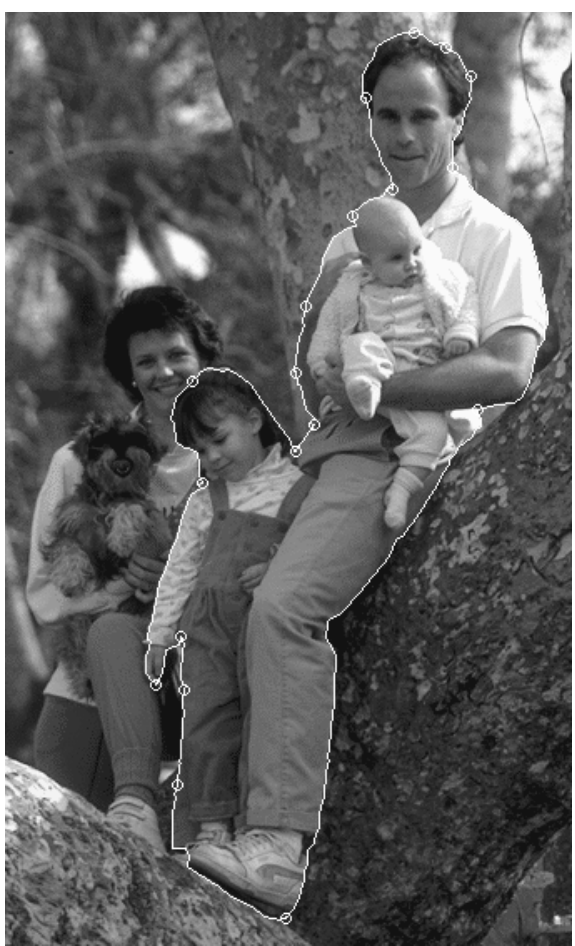

Figure 2: Full color image of a family (size: $340 \times 560)$. Boundary definition with Intelligent Scissors: 18.5 seconds with several seed nodes.

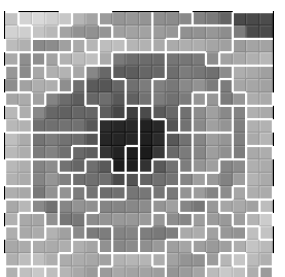

(a)

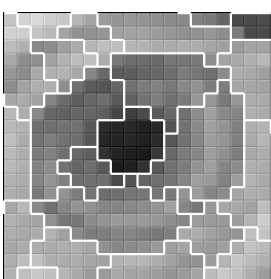

(b)

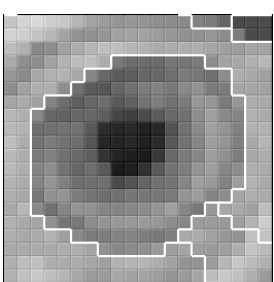

(c)
Figure 3: Hierarchical tobogganing (bird's eye view-from Fig. 4). (a) First level tobogganed regions. (b) Second level (the pupil is now a single region). (c) Third level (the entire eye is a single region).
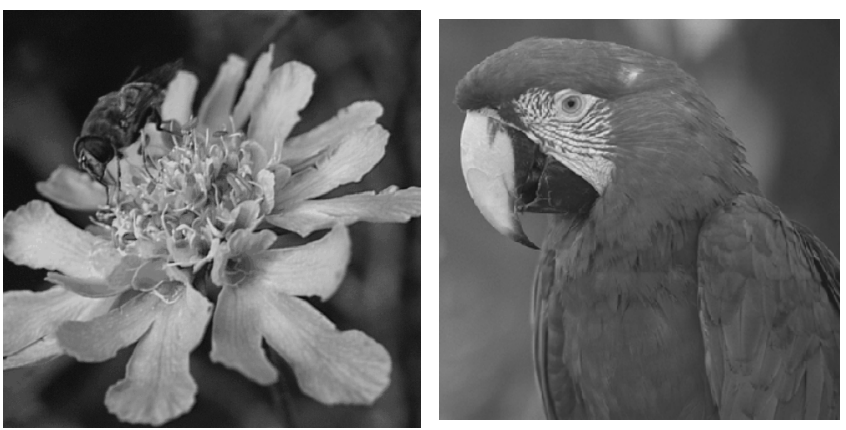

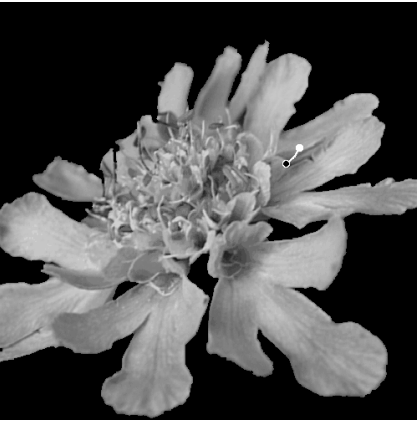

(a)

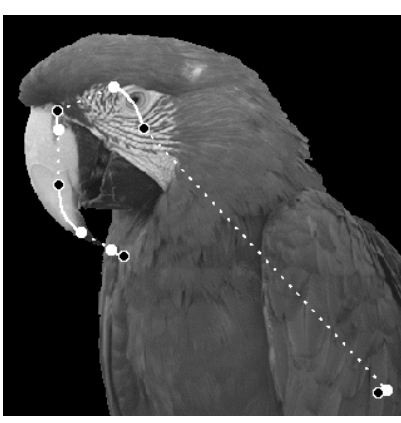

(b)
Figure 4: Full color images of (a) a flower (size: $500 \times 500)$ and (b) a parrot (size: $320 \times 320$ ). Region definition with Intelligent Paint showing the mouse movements (white lines) and mouse clicks (press $\rightarrow$ white circle, release $\rightarrow$ black circle): (a) 2 seconds with 1 mouse click (flower) and (b) 13 seconds with 5 mouse clicks (parrot).

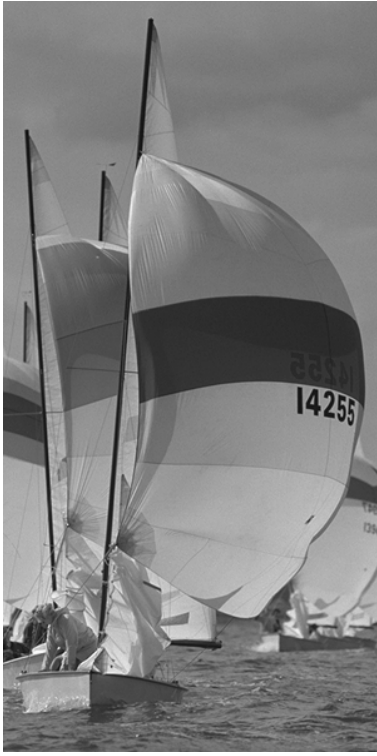

(a)

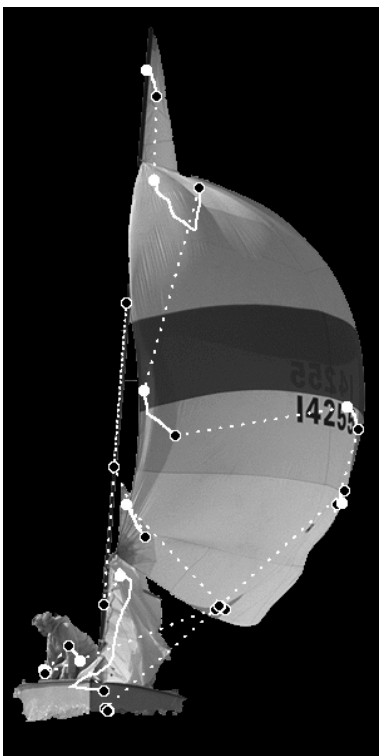

(b)
Figure 5: (a) Full color image of a sailboat. Size: $300 \times 600$. (b) Region definition with Intelligent Paint: 25 seconds with several mouse clicks. 